\title{
Sorption of endrin to montmorillonite and kaolinite clays
}

\author{
Xianjia Peng*, Jun Wang, Bin Fan, Zhaokun Luan \\ State Key Laboratory of Environmental Aquatic Chemistry, Research Center for Eco-Environmental Sciences, Chinese Academy of Sciences, Beijing 100085, China
}

\section{A R T I C L E I N F O}

\section{Article history:}

Received 27 October 2008

Received in revised form 4 January 2009

Accepted 3 February 2009

Available online 13 February 2009

\section{Keywords:}

Persistent organic pollutants

Clay

Soil

Sediment

\begin{abstract}
A B S T R A C T
It has been discovered previously that clay minerals may have a greater potential for sorption of pesticides. In this paper, the sorption of endrin, a nonionic persistent organochlorine pesticide, to montmorillonite and kaolinite was investigated. The effect of $\mathrm{pH}$, ionic strength on the sorption was studied. The effect of intercalation of hydroxyl aluminium species on sorption of endrin to montmorillonite was also investigated. The results show that, the sorption isotherm of endrin to montmorillonite and kaolinite was linear. The sorption increases with the increase in ionic strength. $\mathrm{pH}$ has effect on the sorption and the sorption on both montmorillonite and kaolinite has obvious troughs at $\mathrm{pH}$ about 7.2 and 5.4, respectively. The intercalation of hydroxyl aluminium species decreases the sorption. Sorption mechanism of endrin to montmorillonite and kaolinite was suggested to be a combination of hydrophobic interaction and charge-dipole interaction and troughs in the effect of $\mathrm{pH}$ on sorption was attributed to the proton shift reaction of the broken bonds at the clay edges.
\end{abstract}

(C) 2009 Elsevier B.V. All rights reserved.

\section{Introduction}

The fate of persistent organic pollutants (POPs) in soils and sediments has been of great concern due to their toxicity, persistency and bioaccumulation. Sorption is an important process determining the fate of POPs in soils and sediments.

It has been recognized that organic matter acts as a predominant phase for the sorption of organic contaminants [1-12]. However, other studies $[13,14]$ have discovered that clay minerals may also have a greater potential for sorption of organic contaminants due to their large surface area and their widespread occurrence. It was generally concluded that, for the sorption of organic contaminants, clay minerals play an important role when the clay to organic matter ratio was sufficiently high (i.e., >10-30), especially for polar organic compounds [15].

In recent years, the sorption of organic pollutants to clay minerals has been of a concern of many researchers. For example de Oliveira et al. [16], investigated the sorption of carbaryl on smectite from aqueous suspension using Fourier transform infrared, high-performance liquid chromatography and quantum chemical methods. It was found that sorption of carbaryl strongly depends on the nature of the exchangeable cation and it was indicated that carbaryl sorption is due, in part, to site-specific interactions between the carbamate functional group and exchangeable cations. Rytwo et al. [17] studied the sorption of difenzoquat (DZ) on montmorillonite and found that maximal adsorbed amounts exceeded slightly

\footnotetext{
* Corresponding author. Tel.: +86 10 62849198; fax: +861062849198.

E-mail address: xjpeng@rcees.ac.cn (X. Peng).
}

the cation exchange capacity of the clay. Li et al. [18] studied the thermodynamics of nitroaromatic compound sorption from water by smectite clay and the sorption was found to be an exothermic process on both homoionic $\mathrm{K}^{+}$- and $\mathrm{Ca}^{2+}$-smectite. Chappell et al. [19] investigated the cosorption of atrazine and lauryl polyoxyethylene oxide nonionic surfactant on smectite and found surfactant Brij concentrations of 50 and $200 \mathrm{mg} \mathrm{L}^{-1}$ had little effect on atrazine sorption, but sorption was substantially inhibited by Brij concentrations of $2100 \mathrm{mg} \mathrm{L}^{-1}$.

Organochlorine pesticides are known to be one of the most persistent organic pollutants present in the environment. They have high toxicity, chemical stability, biological stability, lipophilicity and tend to accumulate in organisms. These aforementioned characteristics make the organochlorine pesticides prone to bioaccumulation along the food chain involving a wide range of trophic levels [20]. In order to understand the effect of organochlorine pesticides on environment and human health, it is important to investigate their fate in the environment. In this paper, the sorption of endrin, a polar nonionic persistent organic pollutant organicchlorine pesticide, to two kinds of clay minerals, montmorillonite and kaolinite, was studied and the sorption mechanism was suggested to be a combination of hydrophobic interaction and charge-dipole interaction.

\section{Experimental}

\subsection{Materials}

Montmorillonite and kaolinite used were obtained from Hubei Province, China. Before using, montmorillonite was purified using 
Table 1

Specific surface area, pore volume and average pore size of montmorillonite and kaolinite.

\begin{tabular}{llll}
\hline & $\begin{array}{l}\text { Specific surface } \\
\text { area }\left(\mathrm{m}^{2} \mathrm{~g}^{-1}\right)\end{array}$ & $\begin{array}{l}\text { Pore volume } \\
\left(\mathrm{mLg}^{-1}\right)\end{array}$ & $\begin{array}{l}\text { Average pore } \\
\text { size }(\mathrm{nm})\end{array}$ \\
\hline Montmorillonite & 14.1 & 0.038 & 10.9 \\
Kaolinite & 17.7 & 0.102 & 23.4 \\
\hline
\end{tabular}

sedimentation method and kaolinite was used as received. The purity of kaolinite and purified montmorillonite is $88 \%$ and $89 \%$, respectively and the particle size of montmorillonite and kaolinite is particle size $<0.075 \mathrm{~mm}$. The specific surface area, pore volume, average pore size were shown in Table 1 . Endrin with purity of $>99 \%$ was obtained from Riedel-de Haen AG Seelze-Hannover. n-Hexane was of pesticide grade. Other chemical reagents were all of analytical grade. Ultra-pure water was used throughout the experiments.

\subsection{Methods}

Na-montmorillonite was prepared by adding $5 \mathrm{~g}$ montmorillonite in $250 \mathrm{~mL} 0.5 \mathrm{M} \mathrm{NaCl}$ solution, stirred for $24 \mathrm{~h}$ and washed till chloride free. Hydroxyl aluminium montmorillonite was prepared similarly to procedures described by Saninno et al. [21]. $5 \mathrm{~g}$ montmorillonite was added to $150 \mathrm{~mL}$ water and stirred for $10 \mathrm{~min}$. Then certain volume of $0.2 \mathrm{M} \mathrm{AlCl}_{3}$ was added to the suspension and $0.1 \mathrm{M} \mathrm{NaOH}$ was added to the mixture till $\mathrm{pH}$ reached 6.5. The suspension was further stirred for $1 \mathrm{~h}$, centrifuged and washed till chloride free.

Zeta potentials were measured by microelectrophoresis using a Malven model Zetasizer 2000 zeta potential analyzer. The zeta potentials of the clay particle suspensions containing $0.02 \%$ solid in $0.01 \mathrm{M} \mathrm{NaCl}$ were determined at various $\mathrm{pH}$ values.

Before the sorption test, the endrin stock solution was prepared by dissolving a certain amount of endrin in a known volume of ultra-pure water. Then the concentration of the stock solution was measured and the stock solution was diluted to certain concentrations. Batch sorption experiments were performed in $100 \mathrm{~mL}$ screwed polytetrafluoroethylene (PTFE) centrifuge tubes. To each tube, $40 \mathrm{~mL}$ endrin solution of prescribed concentration and certain amount of sorbent were added. The $\mathrm{pH}$ was adjusted using $1 \mathrm{M} \mathrm{HCl}$ or $1 \mathrm{M} \mathrm{NaOH}$. Then the tubes were shaken on a HZQ-C shaker at $20^{\circ} \mathrm{C}$. Preliminary experiments show that the sorption reaches equilibrium with $24 \mathrm{~h}$, so all the samples were shaken for $24 \mathrm{~h}$. Control samples (endrin solution without clay) were prepared for calibration to quantify endrin loss due to other processes and mass loss of solutes in the control experiments was less than $4 \%$ of the initial concentrations.

After sorption, the mixture was centrifuged and the supernatant solution was decanted and extracted using n-hexane. The endrin concentration was analysed using a Shimadzu GC-14C gas chromatography equipped with an electron capture detector (ECD) using external stands. All sorption experiments were conducted in double and the average value was used. Endrin sorbed was calculated as follows:

$q=\frac{C_{0}-C_{t}}{m}$

where $q$ is the endrin adsorbed $\left(\mu \mathrm{gg}^{-1}\right) ; C_{0}$ the initial endrin concentration $\left(\mu \mathrm{g} \mathrm{L}^{-1}\right) ; C_{t}$ the concentration of endrin after being shaken for a certain period of time $\left(\mu \mathrm{gL}^{-1}\right) ; m$ is the adsorbent dosage $\left(\mathrm{g} \mathrm{L}^{-1}\right)$.

\section{Results and discussion}

\subsection{Sorption isotherms}

Sorption isotherm study was carried out by varying the initial concentration of endrin in the range of $0.5-5.0 \mu \mathrm{g} \mathrm{L}^{-1}$ and the sorption isotherms for endrin from aqueous solution to montmorillonite and kaolinite were shown in Fig. 1. The sorption of endrin to montmorillonite and kaolinite was linear in the concentration range employed. The sorption isotherms were fitted to the following linear model:

$Q=K C_{e}$

where $Q$ is the amount of endrin adsorbed by clays, $C_{e}$ is the equilibrium concentration, $K$ is the sorption coefficient. The sorption data fitted the linear model well with correlation coefficients of 0.97 and 0.98 for montmorillonite and kaolinite, respectively. The $K$ values for sorption of endrin to montmorillonite and kaolinite are 0.18 and $0.21 \mathrm{Lg}^{-1}$, respectively.

\subsection{Effect of $p H$, ion strength on sorption}

Fig. 2 shows the zeta potentials of montmorillonite and kaolinite particles in water. It is shown that, during the $\mathrm{pH}$ range of $2-12$, both montmorillonite and kaolinite particles have negative zeta potentials and the potentials decrease with the increase in $\mathrm{pH}$. The negative zeta potentials of montmorillonite and kaolinite in water indicate that, the clay particles are negatively charged in water. Montmorillonite and kaolinite are layer-structured clays and composed of unit layers, which consist of $\mathrm{Al}^{3+}$ octahedral and $\mathrm{Si}^{4+}$ tetrahedral sheets. Montmorillonite is a 2:1 type of clay mineral, and its unit layer structure consists of one $\mathrm{Al}^{3+}$ octahedral sheet placed between two $\mathrm{Si}^{4+}$ tetrahedral sheets. Kaolinite is a 1:1 type

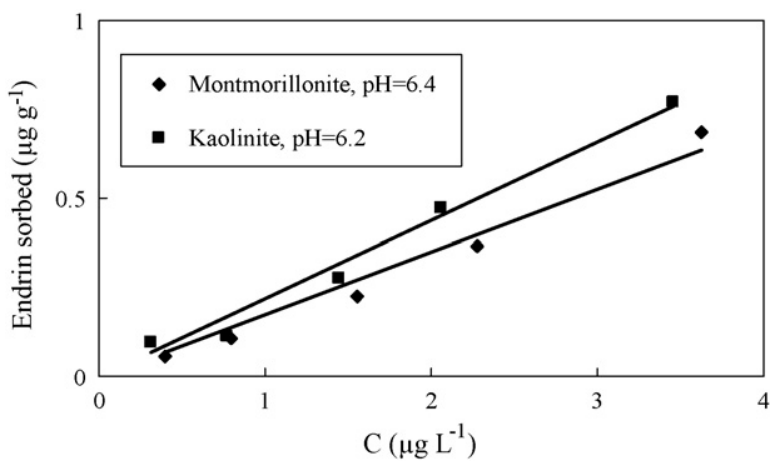

Fig. 1. Isotherms for sorption of endrin to montmorillonite and kaolinite.

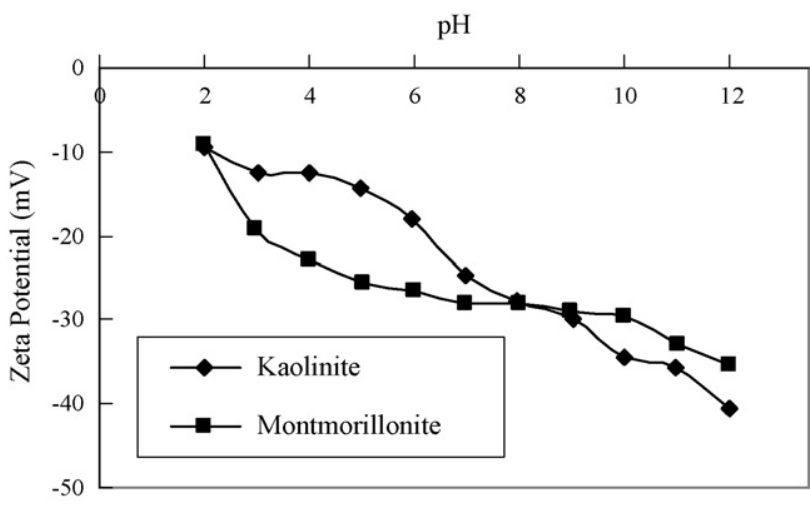

Fig. 2. Zeta potentials of montmorillonite and kaolinite. 


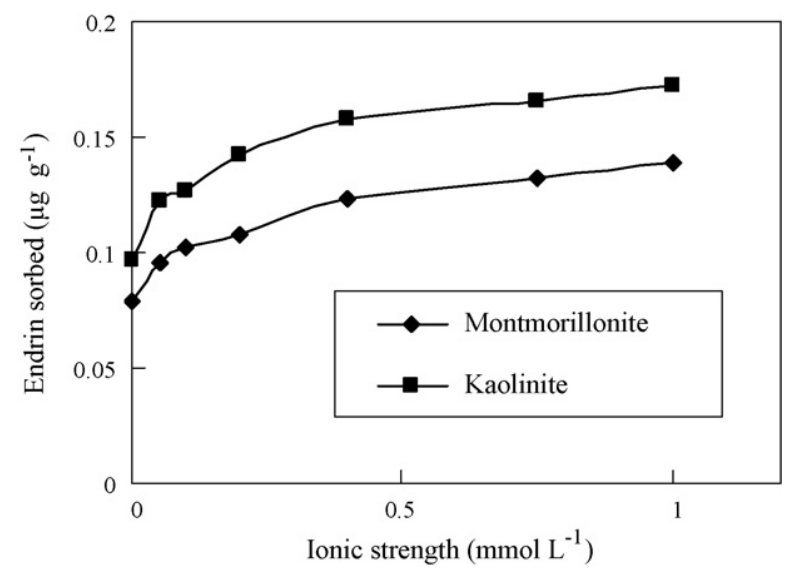

Fig. 3. Effect of ionic strength on sorption of endrin to montmorillonite and kaolinite.

of clay mineral, and its unit layer structure consists of one $\mathrm{Al}^{3+}$ octahedral sheet staked on one $\mathrm{Si}^{4+}$ tetrahedral sheet. In the tetrahedral sheets, $\mathrm{Al}^{3+}$ can substitute for $\mathrm{Si}^{4+}$; in the octahedral sheets, $\mathrm{Mg}^{2+}$ can substitute for $\mathrm{Al}^{3+}$. These isomorphous substitutions in the mineral lattice cause permanent net negative charges at the clay-mineral surface [22]. These negative charges may have great effect on the sorption properties of clays.

Ionic strength may be an important factor affecting sorption process. In this study, the effect of ionic strength on the sorption was investigated. The ionic strength of the solution was adjusted using $\mathrm{NaCl}$. The results were shown in Fig. 3. As can be seen, an increase in ionic strength results in an increase in the sorption for both montmorillonite and kaolinite. The increase of sorption with the increase in the ionic strength maybe is due to the fact that solution ionic strength influences the double layer thickness of clays [23]. The addition of salt results in the compression of the diffuse double layer and facilitates the interaction between endrin molecules and clay surface.

Fig. 4A and $\mathrm{B}$ shows the effect of $\mathrm{pH}$ on sorption of endrin to montmorillonite and kaolinite, respectively. It can be seen that, $\mathrm{pH}$ has effect on sorption of endrin to both montmorillonite and kaolinite. The sorption on both montmorillonite and kaolinite has obvious troughs at $\mathrm{pH}_{\min }$ and $\mathrm{pH}_{\min }$ occurs at about 7.2 and 5.4, respectively.
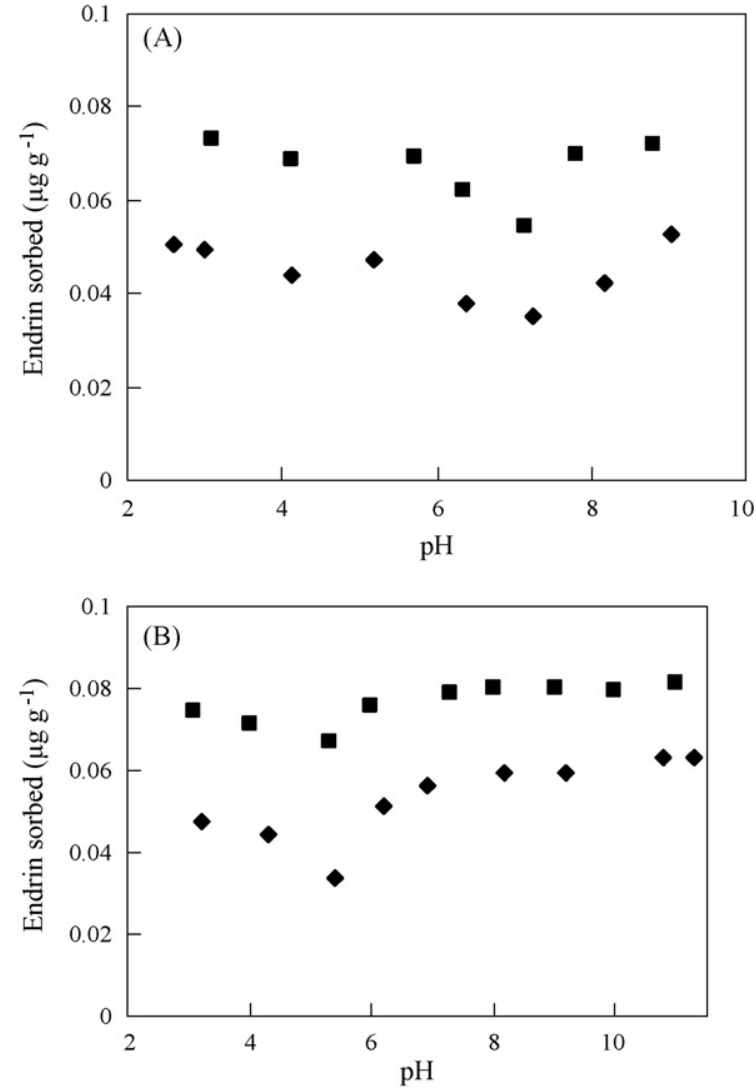

Fig. 4. Effect of $\mathrm{pH}$ on sorption of endrin to montmorillonite and kaolinite.

to montmorillonite and kaolinite is suggested to be a combination of hydrophobic interaction and a charge-dipole interaction. As mentioned above, there exist permanent negative charges resulting from isomorphous substitution in clay structures. Otherwise, around the edges of the silica-alumina units, there are broken bonds, which would give rise to unsatisfied charges [25]. Unlike the permanent negative charges, the edge charges are changeable. This is due to the following proton shift reaction:

$$
\left[\begin{array}{c}
\mathrm{OH}_{2} \\
1 \\
\mathrm{Al}- \\
1
\end{array}\right]
$$

At $\mathrm{pH}<\mathrm{pH}_{\mathrm{min}}$, the sorption decreases with the increase in $\mathrm{pH}$. At $\mathrm{pH}>\mathrm{pH}_{\mathrm{min}}$, the sorption increases with the increase in $\mathrm{pH}$.

It has been previously discovered that the uncharged regions between charge sites on clay siloxane surface show partial hydrophobic character [24]. The hydrophobic interaction between the uncharged regions and the organic molecules may account for the sorption. However, in this investigation, the effect of ionic strength and $\mathrm{pH}$ on the sorption indicates that a chargerelated process may also account for the sorption of endrin to montmorillonite and kaolinite. This sorption mechanism can be suggested to be a charge-dipole interaction between clay charges and endrin molecules (Scheme 1.). Sorption mechanism of endrin

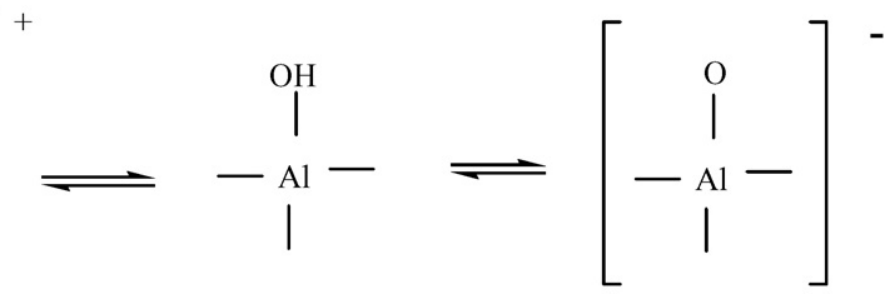

The edge charges change with the change in $\mathrm{pH}$. They are positively charged at low $\mathrm{pH}$ values and negatively charged at high $\mathrm{pH}$ values and there is a zero point of charge on the clay edges $\left(\mathrm{PZC}_{\mathrm{e}}\right)$.

The troughs in the effect of $\mathrm{pH}$ on sorption maybe are caused by the change of edge charges with the change of $\mathrm{pH}$. At $\mathrm{pH}<\mathrm{PZC}_{\mathrm{e}}$, $-\mathrm{OH}_{2}{ }^{+}$groups on the edges was prone to be neutralized to $-\mathrm{OH}$ groups with the increase in $\mathrm{pH}$ and the positive charges were decreased. The decrease of the positive edge charges reduced the charge-dipolar interaction and resulted in the decreased sorption. At $\mathrm{pH}>\mathrm{PZC}_{\mathrm{e}},-\mathrm{OH}$ groups on the edges was prone to be ionized with the increase in $\mathrm{pH}$ and the edges were more and more negatively charged. The increase of negative edge charge enhanced the charge-dipolar interaction and resulted in the increased sorption. 


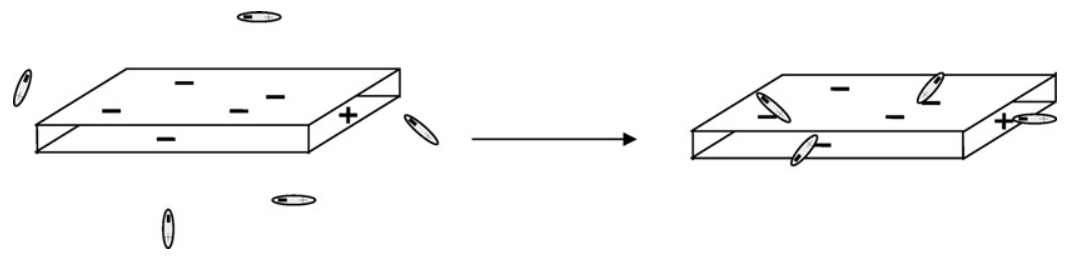

Scheme 1. Charge-dipole interaction between clay charges and endrin molecules.

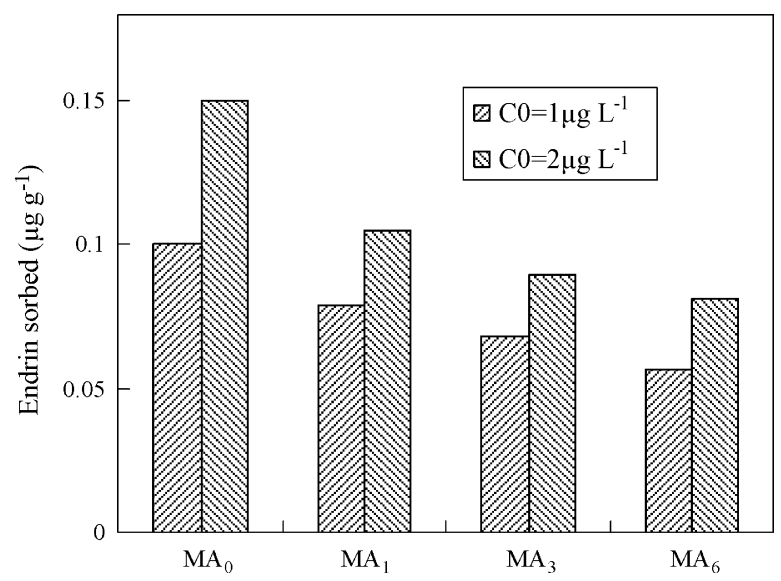

Fig. 5. Effect of intercalated hydroxyl aluminium on sorption of endrin to montmorillonite.

\subsection{Effect of intercalated hydroxyl aluminium on sorption to montmorillonite}

Unlike kaolinite, montmorillonite has exchangeable cations in the interlayer space. These exchangeable can be intercalated by hydroxyl metal species through the exchange of interlayer cations and hydroxyl metal species. In this section, the effect of interlayer cations $\left(\mathrm{Na}^{+}, \mathrm{K}^{+}, \mathrm{Ca}^{2+}\right)$ and intercalated hydroxyl metal species (hydroxyl aluminium species) on sorption of endrin to montmorillonite was investigated.

The effect of intercalated hydroxyl aluminium species was shown in Fig. 5. Three kinds of hydroxyl aluminium-intercalated montmorillonites with aluminium/montmorillonite preparation ratios of $1,3,6 \mathrm{mmolg}^{-1}$, which were denoted as $\mathrm{MA}_{1}, \mathrm{MA}_{3}$, $\mathrm{MA}_{6}$ respectively, were used in the study. $\mathrm{Na}$-montmorillonite without hydroxyl aluminium species intercalation was denoted as $M A_{0}$. The XRD patterns showed that, the interlayer spacings of $\mathrm{MA}_{1}, \mathrm{MA}_{3}, \mathrm{MA}_{6}$ were $1.50,1.68,1.73 \mathrm{~nm}$, respectively, which were higher than the original $\mathrm{Na}$-montmorillonite $(1.23 \mathrm{~nm})$ and indicated that hydroxyl aluminium species has been intercalated into the interlayer space. The results show that the intercalated hydroxyl aluminium species has effect on the sorption and the sorption decreases with the increase in aluminium/montmorillonite ratio. For example, at initial endrin concentration of $1 \mu \mathrm{g} \mathrm{L}^{-1}$, endrin sorbed on $\mathrm{MA}_{0}, \mathrm{MA}_{1}, \mathrm{MA}_{3}, \mathrm{MA}_{6}$ was $0.100,0.079,0.068$, $0.057 \mu \mathrm{gg}^{-1}$. The decreased sorption with the increase in aluminium/montmorillonite ratio maybe is due to the fact that the intercalation of hydroxyl aluminium species results in the reduction of montmorillonite charges.

\section{Conclusions}

(1) The sorption isotherm of endrin to montmorillonite and kaolinite was linear. The sorption increases with the increase in ionic strength.
(2) $\mathrm{pH}$ has effect on the sorption. The sorption on both montmorillonite and kaolinite has obvious troughs at $\mathrm{pH}$ about 7.2 and 5.4 , respectively.

(3) The intercalation of hydroxyl aluminium species into montmorillonite interlayer decreases endrin sorption to montmorillonite.

(4) Sorption mechanism of endrin to montmorillonite and kaolinite was suggested to be a combination of hydrophobic interaction and charge-dipole interaction and troughs in the effect of $\mathrm{pH}$ on sorption was attributed to the proton shift reaction of the broken bonds at the clay edges.

\section{Acknowledgements}

This work was supported by National Natural Science Foundation of China (Grant Nos. 50538090, 20607027).

\section{References}

[1] C.T. Chiou, L.J. Peters, V.H. Freed, Physical concept of soil-water equilibria for nonionic organic compounds, Science 206 (1979) 831-832.

[2] S.W. Karickhoff, D.S. Brown, T.A. Scott, Sorption of hydrophobic pollutants on natural sediments, Water Res. 13 (1979) 241-248.

[3] C.T. Chiou, P.E. Porter, D.W. Schmedding, Partition equilibria of nonionic organic compounds between soil organic matter and water, Environ. Sci. Technol. 17 (1983) 227-231.

[4] D.E. Kile, C.T. Chiou, H. Zhou, H. Li, O. Xu, Partition of nonpolar organic pollutants from water to soil and sediment organic matters, Environ. Sci. Technol. 29 (1995) 1401-1406.

[5] J.J. Pignatello, B. Xing, Mechanisms of slow sorption of organic chemicals to natural particles, Environ. Sci. Technol. 30 (1996) 1-11.

[6] W.J. Weber, W.A. Huang, A distributed reactivity model for sorption by soils and sediments. 4. Intraparticle heterogeneity and phase distribution relations under nonequilibrium, Environ. Sci. Technol. 30 (1996) 881-888.

[7] W.Huang, T.M. Young, M.A.Schlautman, H.Yu, W.J. Weber, A distributed reactivity model for sorption by soils and sediments. 9. General isotherm nonlinearity and applicability of the dual reactive domain model, Environ. Sci. Technol. 31 (1997) 1703-1710.

[8] E.J. Leboeuf, W.J. Weber, A distributed reactivity model for sorption by soils and sediments. 8. Sorbent organic domains: discovery of a humic acid glass transition and an argument for a polymer-based model, Environ. Sci. Technol. 31 (1997) 1697-1702.

[9] B. Xing, J.J. Pignatello, Dual mode sorption of low polarity compounds in glassy poly (vinylchloride) and soil organic matter, Environ. Sci. Technol. 31 (1997) 792-799.

[10] S. Kleineidam, H. Rugner, B. Ligouis, P. Grathwohl, Organic matter facies and equilibrium sorption phenanthrene, Environ. Sci. Technol. 33 (1999) 1637-1644.

[11] C.T. Chiou, D.E. Kile, D.W. Rutherford, G. Sheng, S.A. Boyd, Sorption of selected organic compounds from water to a peat soil and its humic-acid and humin fractions: potential sources of the sorption nonlinearity, Environ. Sci. Technol. 34 (2000) 1254-1258.

[12] G. Xia, W.P. Ball, Polanyi-based models for the competitive sorption of lowpolarity organic contaminants on a natural sorbent, Environ. Sci. Technol. 34 (2000) 1246-1254.

[13] G.W. Bailey, J.L. White, T. Rothberg, Adsorption of organic herbicides by montmorillonite: role of $\mathrm{pH}$ and chemical character of adsorbate, Soil Sci. Soc. Am. Proc. 32 (1968) 222-234.

[14] D.A. Laird, E. Barriuso, R.H. Dowdy, W.C. Koskinen, Adsorption of atrazine on smectites, Soil Sci. Soc. Am. J. 56 (1992) 62-67.

[15] S.A. Boyd, G. Sheng, B.J. Teppen, C.T. Johnston, Mechanisms for the adsorption of substituted nitrobenzenes by smectite clays, Environ. Sci. Technol. 35 (2001) 4227-4234.

[16] M.F. de Oliveira, C.T. Johnston, G.S. Premachandra, J. Brian, B.J. Teppen, H. Li, D.A. Laird, D. Zhu, S.A. Boyd, Spectroscopic study of carbaryl sorption on smectite from aqueous suspension, Environ. Sci. Technol. 39 (2005) 9123-9129. 
[17] G. Rytwo, M. Tavasi, S. Afuta, S. Nir, Adsorption of difenzoquat on montmorillonite: model calculations and increase in hydrophobicity, Appl. Clay Sci. 24 (2004) 149-157.

[18] H. Li, B.J. Teppen, C.T. Johnston, S.A. Boyd, Thermodynamics of nitroaromatic compound adsorption from water by smectite clay, Environ. Sci. Technol. 38 (2004) 5433-5442.

[19] M.A. Chappell, D.A. Laird, M.L. Thompson, V.P. Evangelou, Cosorption of atrazine and a lauryl polyoxyethylene nonionic surfactant on smectite, J. Agric. Food Chem. 53 (2005) 10127-10133.

[20] J.L. Raposo Jr., N. Ré-Poppi, Determination of organochlorine pesticides in ground water samples using solid-phase microextraction by gas chromatography - electron capture detection, Talanta 72 (2007) 1833-1841.
[21] F. Sannino, A. Violante, L. Gianfreda, Adsorption-desorption of 2,4-D by hydroxy aluminium montmorillonite complexes, Pestic. Sci. 51 (1997) 429-435.

[22] J.A. Smith, A. Galan, Sorption of nonionic organic contaminants to single and dual organic cation bentonite from water, Environ. Sci. Technol. 29 (1995) 685-692.

[23] J. Gao, J.A. Pedersen, Adsorption of sulfonamide antimicrobial agents to clay minerals, Environ. Sci. Technol. 39 (2005) 9509-9516.

[24] W.F. Jaynes, S.A. Boyd, J. Air Waste Manage. Assoc. 40 (1990) 1649-1653.

[25] R.E. Grim, Clay Mineralogy, McGraw-Hill Book Company Inc., New York 1953. 